\title{
Noble gas analysis and microstructure observation of metasomatized peridotite from the Finero phlogopite- peridotite massif, Southern Alps, Italy
}

\author{
NANAE FUKUSHIMA ${ }^{1}$, HIROCHIKA SUMINO ${ }^{1}$, JUN-ICHI \\ ANDO $^{2}$, DAS KAUSHIK ${ }^{2}$, MASAHIRO KOBAYASHI ${ }^{3}$, \\ HIROYUKI KAGI ${ }^{4}$ AND TAKAFUMI YAMAMOTO ${ }^{2}$ \\ ${ }^{1}$ The University of Tokyo \\ ${ }^{2}$ Hiroshima University \\ ${ }^{3}$ Tokyo Metropolitan Industrial Technology Research Institute \\ ${ }^{4}$ University of Tokyo \\ Presenting Author: fukushima-nanae322@g.ecc.u-tokyo.ac.jp
}

Since the rheology of mantle controls the behavior of deep earthquakes and orogenic activity, it is important to understand elementary processes of deformation of the mantle rocks. Notably, the addition of water in mantle region has a significant effect on its rheology and chemical properties.

We focus on the effect of water on the deformation characteristics preserved in the Finero phlogopite peridotite, which is an alpine-type peridotite and had been metasomatized by slab dehydration in the mantle wedge during the Paleozoic and Mesozoic(Selverstone \& Sharp, EPSL 2011; Hartmann \& Wedepohl, GCA 1993; Zanetti et al.,Contrib. Mineral. Petrol. 1999).

To clarify the water-rock interaction and deformation history of the peridotite, we performed: (1) microstructural observations using a scanning electron microscope and a transmission electron microscope, and (2) noble gas analysis of fluid/melt inclusions in mineral grains, which provide information of the origin of fluids/melts. For the noble gas analysis, the crushing method was adopted to selectively extract noble gases from fluid/melt inclusions.

In the field survey, we found a strain localization zone about $80 \mathrm{~m}$ wide in the peridotite, and collected rocks in the strain localization zone and $750 \mathrm{~m}$ away from the strain localization zone, respectively.

The results of the olivine slip system observation suggest that fluid may have penetrated the rock of the strain localization zone during brittle-ductile deformation.

Noble gas analyses of fluid/melt inclusions showed that He, $\mathrm{Ne}$, and Ar isotope ratios of all samples can be accounted for by three-component mixing of atmosphere/seawater, radiogenic/nucleogenic and mantle components. Similar mixing relation has been observed in very fine-grained apatite and orthopyroxene separated from the Finero peridotite (Matsumoto et al., EPSL 2005). On the other hand, the Ne-Ar-Xe elemental ratios of the samples show that a seawater-derived component is dominant. In addition, while $3 \mathrm{He} / 4 \mathrm{He}$ ratios are uniform, $40 \mathrm{Ar} / 36 \mathrm{Ar}$ ratios become lower with increasing deformation of the sample rock. This suggests that the seawater-derived component may have added to the mantle + radiogenic/nucleogenic component, and that the metasomatism by slab-derived, water-rich fluids may have promoted plastic deformation of peridotite in the mantle region. 